\title{
Production ecosystems and platforms development in the industry digital transformation conditions
}

\author{
Nataliya Kashevarova ${ }^{1}$, Vladimir Shiboldenkov ${ }^{2}$ \\ ${ }^{1}$ Associate professor of department «Entrepreneurship and international business», Cand. Sc. (Econ.), \\ Bauman Moscow State Technical University, Moscow; \\ ${ }^{2}$ Assistant professor of department «Entrepreneurship and international business», Cand. Sc. (Econ.), \\ Bauman Moscow State Technical University, Moscow
}

\begin{abstract}
Current trends and prospects for the development of integrated production systems in the context of digital transformation are considered. the key trends are the creation of digital duplicates of industrial processes, the development of platform solutions and production ecosystems, as well as increasing the flexibility of production business processes. The importance of forming production and consumer ecosystems for business growth is shown.

Keywords: organization of production, digital economy, digitalization of business processes, digital production, integrated production ecosystems.
\end{abstract}

\section{Introduction}

Modern production systems are characterized by significant high technology production processes. In this regard, their organization requires the introduction of digital economy tools and the formation of a flexible, transparent and easily scalable system of fully digitized organization activities [1].

The processes of industry digitization in modern conditions imply the formation of an algorithmic model of the enterprise and all its components [1], while industry barriers are destroyed and new niches for business are created. Together with this, previously effective business models are destroyed. It is also important to note that the digitalization processes of production systems are closely related to the development of knowledge management methods [2], as well as to the increasing importance of cognitive production factors [3, 4]. Most enterprises currently view the business environment as networks of interdependent elements, which are combined to create value. The spread of cloud technology, industrial Internet, and $3 \mathrm{D}$ printing leads to the fact that the creation of an ecosystem becomes not only a tool for increasing the efficiency of certain types of activities, but also a means of business growth and expansion [5].

A new stage in the scientific, technical and socio-economic development of the modern world is characterized by deep changes not only at the level of elements of integrated industrial structures (key factors of production, fundamental technologies, basic industries), but also by a global reorganization of the mechanisms of communication, connections, and interaction between them. Thus, around a key promising cross-cutting technology, not only 
a complex production and economic system is formed, which is called the high-tech sector of the economy, but a consistent integrated system that synergistically connects complex communities consisting of research, production, technological, financial and investment, socio-political and educational subsystems [6].

Abroad, examples of integrated production structures (IPS) of different levels - are systems of different economic and institutional scales [6,7]:

- corporate macro-technological structures: IT sector (Apple, Samsung, Huawei), engineering sector (Ford, Tesla), aerospace sector (Boeing, Lockheed Martin), biotechnology sector (DuPont, Bayer);

- regional: ABB, DeWALT;

- state: Electrolux, Siemens, Cisco;

- Integrated multinational multisector structures: Daimler, Monsanto, Unilever, Brother.

In the digital economy, IPS used to be an ecosystem in which there are an open environment is created to stimulate, produce and spread innovations. Currently, the leaders in creating such ecosystems are the flagship IT conglomerates: foreign western FAANG (Facebook, Amazon, Apple, Netflix, Google), Chinese Tencent and Alibaba, and domestic (Sberbank, Yandex, Mail.ru). They are leaders due to the fact that they have a set of digital solutions that perform the algorithmization of many tasks related to financial activities and the field of services and digital goods. But it is worth noting, that this business model is used not only by information technology, but also traditional industrial conglomerates, such as Nike, Adidas, Unilever, Procter \& Gamble, etc. For example, the BMW Group and Microsoft have created an open production platform aimed at the development of industrial Internet technologies in the automotive and other industries [8].

The analysis of modern processes of digital transformation of economic and production systems has revealed the features of the development of innovation production infrastructure. In the digital economy, the core of the industry market forms a basic technology package - a group of technologies and processes that are functionally strongly interconnected, but they are different in their nature. In turn, the most important component of any basic package are smart digital technologies, considered in the work as a single system of data, knowledge, methods of their processing and transfer.

The formation of the global economic system, the decentralization of the organizational structure, the intensification of command and project mechanisms of management, the widespread use of cross-cultural communication transforms the tasks of managing the production system into complex interdisciplinary events.

The peculiarity of the study of the economic macro-system is based on the interdisciplinarity of the research, which consists of the development and convergence of the digital humanities in the application of artificial intelligence and cognitive technologies to the study of subject areas at the intersection of econometrics, sociology, political science, anthropology and psychology. At the same time, the practice of analyzing and managing the global macroeconomic system requires the development of scientifically based recommendations for operational anti-crisis measures, continuous optimization of the organizational structures of industrial enterprises during the period of instability, technological and economic shocks inherent in the modern stage of the creative destruction of existing business models and industries [6].

\section{Main trends in the development of integrated production ecosystems}

The current stage of economic development is characterized by an increase in the diffusion of innovations, however, unlike managerial innovations, the transfer and the direct borrowing of elements of a national business culture are not possible. To emulate the 
successes of productive options for national innovation systems, it is necessary to model not only the incremental mechanisms for the creation and transfer of technologies, but also to form the entire structure of the innovation system [6]. Thus, the successful development of industrial enterprises, their adaptation to the conditions of digital transformation and the creation of conditions for the implementation of disruptive innovations are critically dependent on the level of systemic harmonization of the implemented management mechanisms. To date, the following trends in the development of production systems can be identified:

- digital transformation and the creation of digital twins of production processes;

- implementation of platform solutions;

- development of integrated production ecosystems;

- flexible manufacturing business processes.

Digital transformation and the creation of digital twins of production processes. The core of all transformations today is the digital transformation of the economy. All business processes of any organization and even an individual person is displayed in some digital duplicate, for which you need to significantly increase the autonomy and intelligence of the entire business ecosystem. After the stages of automation (2005-2010), informatization (2011-2015) and digitalization (2016-2020), according to scientists, there will come a period of "smartization" when objects and systems managed with the help of information and communication technologies become truly "smart" in the power of possessing a number of quasi-intellectual functions [6]. Today, individual work tasks are no longer algorithmized yet, but a complete system-service solution is formed that digitizes the entire business requirements as much as possible. Table 1 presents the typical stages of the digital transformation of the industrial economic system.

Table 1. Typical stages of digital transformation of the industrial economic system

\begin{tabular}{|l|l|}
\hline \multicolumn{1}{|c|}{ Stage } & \multicolumn{1}{c|}{ Tasks } \\
\hline 1. The formation of sources of value & Formalization of business needs and business cases \\
\hline 2. Building a data ecosystem & Aggregation, analysis and identification of valuable data \\
\hline $\begin{array}{l}\text { 3. Selection of technologies and } \\
\text { tools }\end{array}$ & $\begin{array}{l}\text { Finding the right digital business intelligence tools for } \\
\text { your business }\end{array}$ \\
\hline 4. Workflow integration & $\begin{array}{l}\text { Integration of digital intelligent technologies into the } \\
\text { business and optimization of interaction with it }\end{array}$ \\
\hline 5. Creating a digital organization & $\begin{array}{l}\text { Creating an open, complementary culture of employees } \\
\text { and digital intelligent technologies }\end{array}$ \\
\hline
\end{tabular}

A digital twin is a virtual digital model of a complex socio-economic system, taking into account the dynamics of the interaction of complex objects at all stages of the life cycle. In a general sense, the concept of a digital twin is an information model that differs in the key properties [7,9] of visibility, realism, and interactivity.

Strategically, digital production and digital production processes integrates virtual models of digital twins with real objects through the cyberphysical elements of factory infrastructure and provides effective real-time control and response to environmental changes [10]. In the applied sense, a digital twin is considered to be a fully interactive digital product analogue, on which one could perform various virtual manipulations and experiments with any part and elements at any stage of its life cycle (idea generation - designing - testing - maintenance disposal).

Statistics on the use of technology of digital twin products shows a reduction in unnecessary and unplanned operations by 2 times, time costs by 12 times, financial costs by 10 times. The market for software solutions in the field of digital doubles of production processes for 2019-2020 is \$ 16 billion [9]. Market leaders are states with a developed digital economy: USA - 7.7 billion; Japan - 3.82 billion; Germany - 3.75 billion. The market for 
digitalization of production solutions is reaching the maturity phase: the stage of high expectations has passed, large competent players in the field of engineering software have grown, and a state industrial policy in the field of digital economy has formed.

Implementation of platform solutions. Currently, a new "business model" is actively developing - the platform. Often, platforms are the result of solving the company's internal data management tasks. One of the tasks of digital transformation of an organization is to assess the transformational potential of a business. After analyzing the business opportunities for integrated transformations, it is possible to draw up strategies for a system platform solution. Digital platform solutions are the functional combination of software and hardware elements of a single architecture for the complex solution of economic problems [11], which allows two or more groups to interact.

Thus, the digital ecosystem is the formation of a new paradigm of the business model with the integration of economic tasks and information \& technological infrastructure, which provides mutually beneficial interaction between the producer and the consumer. Moreover, the digital ecosystem goes beyond traditional industry structures. Ignoring the ecosystems of consumption, industrial companies not only miss the potential growth opportunities, but also ignore the competition risks with digital companies. Such companies as Google, Facebook, Apple, Amazon, and Uber have already begun to influence the ecosystems of consumption of a number of products through their various platforms [9]. For example, Google's smart home systems make the most efficient use of light bulbs. As value shifts from a physical lamp to new services that are emerging in the smart home ecosystem, lamp manufacturers that focus only on manufacturing ecosystems may face cost losses. Thus, in order to maintain competitiveness in the digital age, companies must not only develop their production ecosystems, but also enter into various ecosystems of consumption or create new ones.

The digital management system allows the productive use of a significant asset of a manufacturing enterprise - data on all its processes and activities. Thus, the enterprise has new tools for regulating, managing and predicting its activities on the basis of its own collected arrays of information from sources of various values. Whether it's equipment, workers or customer feedback.

Development of integrated production ecosystems. Digitalization of business processes allows us to reconsider approaches to the business architecture of the enterprise and form new network approaches to creating organizational value with the formation of direct channels of communication with customers and the exclusion of ineffective intermediaries. This kind of integrative transformations of a business model is called ecosystem approaches and networks of value creation [12-14].

The approach of a platform and ecosystem economy is a systematic look at the organization's activities and the development of the value of mutual relations, networks and partnerships with all interested parties of the business in question [9]. In this case, an ecosystem is a form of a business model that consists in the company's own communication system with its customers, users, and other participants in the value chain, minimizing the number of various kinds of contractors.

The capabilities of digital smart technologies expand and transform the capabilities of the organization. Using digital technologies allows one to create a digital ecosystem that integrates a traditional industry structure with digital space: combining digital devices and gadgets, social tools and services, software products and platform solutions [9].

Supply ecosystems are similar to classic industry-specific production and technological conglomerates and complexes that directly connect the processes of production, marketing, sales and services in the provision of goods and services to consumers. In turn, more complex and integral associations are formed in terms of product consumption ecosystems, which generalize the processes of stimulating the development and sale of goods and services offered. This business model fully takes into account the entire life cycle of product 
consumption and pays special attention to the issues of distribution, integration, disposal and after-sales service. The consumption ecosystem represents the development of the wellknown strategy of complementarity of commodity pairs and commodity associations [15], which form combined and complementary structures of goods and services.

In production ecosystems, the relationships between suppliers, research and development, manufacturing or distribution operations are typically tightly attached to processes and not easy to reconfigure. Business process reengineering efforts are time consuming, expensive, and risky. Creating digital production ecosystems could help companies significantly improve the performance of traditional products and services and, in the long run, improve their market position. Thus, industrial companies should strive for digital transformation of their production ecosystem, as well as form an ecosystem of consumption $[15,16]$.

It is the transition from value chains to integrated networks and ecosystems, as well as the expansion of direct and ongoing communication with consumers that provides companies with leadership [17]. In work [9], four business models are identified as they are characteristic for the digital era, two of them involve the development of ecosystems.

A characteristic feature of digital ecosystems is their expansive nature and speed of formation. Some companies have already accepted these changes. However, many enterprises are still focused on competition within traditional industry structures, and they are forced to adapt quickly to new ecosystems, which are based on new digital technologies.

Companies, who are leaders of digital platform solutions and digital duplication of production processes represent the core of industrial innovation ecosystems.

Siemens has formed an open system of interaction with partners in the form of a global platform solution, allowing to unite all entities associated with the Siemens brand. The advantages of the ecosystem approach are the development of cooperation, the influx of ideas, the acceleration of innovation, the development of the flexibility of the corporate structure, the productive adaptation to changes, the joint solution of problems, the marketdriven offer of goods and services to consumer needs, the development of social and human capital [18].

SAP also has an open technology partner ecosystem. The advantages of the approach in the company are the follows: the activity of partners and the expansion of sales channels, a significant share of value due to indirect sales ( $60 \%$ of revenue), standardization of solutions, regulation of proposals for world practices and standard business processes, a corporate implementation methodology, an advanced pricing model, accelerated implementation [ 19].

The Cisco partner ecosystem is also an example of an integrated production system that unites participants in a global network and allows one to stimulate the organization's innovation, optimize distribution, unify computing procedures, design a universal architecture for data centres and virtual data centres, simplify operations, expand one's business and perform system integration [20].

ANSYS also uses an open innovation ecosystem strategy that brings together the organization's engineering modeling partners. The features of the approach are the new sales channels, effective customer service and support, expanding the product portfolio together with providing solutions of a complete package of hardware and software solutions [21].

\section{Results}

Summarizing the above experience, certain premises could be made about the prospects of an integrated ecosystem approach to the structure of an industrial enterprise:

- the ecosystem view extends the organization's product portfolio to a system of integrated and package solutions for a wide pool of goods and services;

- the ecosystem view expands the organization's market opportunities by providing access to new players, market niches and territories; 
- the ecosystem view allows one to increase the growth potential of the organization due to the resource base and cognitive factors of production of the partners of the partner network.

Flexible manufacturing business processes. One of the trends in the formation of production systems is the creation of flexible production systems. According to [22] and [23], the flexibility of production systems implies rapid adaptation to the conditions of a competitive environment based on the effective use of production factors such as speed, flexibility, quality and innovation. In [24], the following aspects of the formation of a flexible organization are highlighted:

- integration: parallel business processes, enterprise integration, the formation of horizontal communication channels;

- team building: cross-functional teams, teams including participants outside the organization, decentralization of decision-making;

- technological development: leadership in the use of modern technologies; continuous staff development and knowledge management;

- quality management: creation of products with significant added value, short development cycle;

- cooperation: strategic relationships with customers and suppliers.

Thus, the principles of flexible production systems are consistent with the concept of production ecosystems. As noted in the review [25], the integration of information technology and the flexibility of the organization's business processes increase the efficiency of the organization's operational management and provide an opportunity for the formation of a flexible supply chain; similarly, internal (cross-functional) and external (with suppliers and customers) integration increases the company's ability to act flexibly within its own chain of value creation.

\section{Conclusions}

The trend of digital business transformation involves the formation of a new business model based on the transformation, digitization and integration of all value flows of any organization. For an industrial enterprise, this is the creation of an integrated production ecosystem. This ensures the strengthening of the competitive potential of the company, enhancing the value of mutual relations and partnership programs, as well as it expands development opportunities, creates new growth points and opens up new horizons for business.

At the same time, a number of problems of slow digital transformation of domestic production should be highlighted:

1. Late start of technology development (7 years later than world leaders).

2. An undeveloped regulatory and legal framework for information security and digital data privacy.

3. Lack of a global strategy for digital duplication of the full production cycle. There are mainly used the incremental initiatives of digital duplication of individual parts, nodes and components.

4. Lack of competencies, resources and capacities to ensure digitalization of production.

5. Conservatism and complexity in the production of technological objects.

6. Psychological inertia in the transition to digital thinking based on data.

The ecosystem trend stimulates the transformation of an organization with traditional specialization into a complex system of placement of its core functions and direct interaction with consumers, partners, regulators and institutions, information technology companies in the form of a more diverse complex of solutions and services [9]. 


\section{References}

1. AI in 2019: 8 trends to watch. [Electronic source]: K. Casey // A community of CIOs discussing the future of business and IT. URL: https://enterprisersproject.com/article/2018/12/ai-trends-2019 (access date: 24.10.2019).

2. Knowledge management capability impact on enterprise performance in Russian hightech sector / E.N. Gorlacheva, A.G. Gudkov, I.N. Omelchenko, P.A. Drogovoz, D.V. Koznov // 2018 IEEE international conference on engineering, technology and innovation, ICE/ITMC 2018 - Proceedings. 2018. Art. No. 8436316. DOI: 10.1109/ICE.2018.8436316.

3. The modelling of the efficiency in the new generation manufacturing distributive systems based on the cognitive productions factors / I.N. Omelchenko, P.A. Drogovoz, E.N. Gorlacheva, V.A. Shiboldenkov, O.M. Yusufova // IOP Conference Series: Materials Science and Engineering. 2019. Vol. 630, Issue 1. Art. No. 012020. DOI: 10.1088/1757899X/630/1/012020.

4. Cognitive factors of production's utility assessment of knowledge-intensive organizations / E.N. Gorlacheva, I.N. Omelchenko, P.A. Drogovoz, O.M. Yusufova, V.A. Shiboldenkov // AIP Conference Proceedings. 2019. Vol. 2171. Art. No. 090005. DOI: 10.1063/1.5133228.

5. Gueguen G. Coopetition and business ecosystems in the information technology sector: the example of Intelligent Mobile Terminals //International journal of entrepreneurship and small business. 2009. V. 8. №. 1. PP. 135-153.

6. Shiboldenkov V.A. Development of tools for neural network intelligence analysis and decision support for the development of economic systems: Thesis for a Candidate Degree in Economic Sciences. M. 2019. 208 p.

7. Dadalko V.A., Nazyrova D.R., Topchiy P.P. Digital Economy Tools to Ensure the Transparency of Managing an Industrial Enterprise // Economy. Taxes. Law. 2018. №5. URL: https://cyberleninka.ru/article/n/instrumenty-tsifrovoy-ekonomiki-kak-sposobyobespecheniya-transparentnosti-hozyaystvovaniya-promyshlennogo-predpriyatiya (access date: 24.10.2019).

8. The open manufacturing platform [Electronic source]: https://www.bmwgroup.com/en/innovation/company/open-manufacturing-cloud.html (access date: 24.10.2019).

9. Weill P., Woerner S. L. Thriving in an increasingly digital ecosystem // MIT Sloan Management Review. 2015. V. 56. №. 4. P. 27.

10. Volochienko V., Falko S., Postnikova E. Recognition of the problematic situations in industrial systems with intellectual support // International Journal of Mathematical, Engineering and Management Sciences. 2019. Vol. 4, № 6. P. 1434-1447.

11. Novozhilov K. S., Golubev D. V., Entin N. I. The core of the digital platform // Colloquium-journal. 2019. №15 (39). URL: https://cyberleninka.ru/article/n/yadrotsifrovoy-platformy-1 (access date: 17.10.2019).

12. Rudskaya E.N., Shikolenko A.G. Banking as a digital ecosystem: problems and trends // Economics and Business: Theory and Practice. 2019. №. 9. P. 141-144.

13. Subramaniam M., Iyer B., Venkatraman V. Competing in digital ecosystems // Business Horizons. 2019. V. 62. №. 1. P. 83-94.

14. Lütjen H. et al. Managing ecosystems for service innovation: A dynamic capability view //Journal of Business Research. 2019. P. 506-519.

15. de Vasconcelos Gomes L. A. et al. Unpacking the innovation ecosystem construct: Evolution, gaps and trends // Technological Forecasting and Social Change. 2018. V. 136. P. 30-48. 
16. Jacobides M. G., Cennamo C., Gawer A. Towards a theory of ecosystems // Strategic Management Journal. 2018. V. 39. №. 8. P. 2255-2276.

17. Petrov A.V. Imitation as the basis of digital twin technology // Bulletin of Irkutsk State Technical University. 2018. V. 22. №. 10 (141). PP. 56-66.

18. How difficult is the transition of industry to a "number" and what benefits will it bring to Russia [Electronic source]: https:/expert.ru/expert/2020/01/pod-znakom-bliznetsov/ (access date: 24.10.2019).

19. About the Siemens Innovation Ecosystem [Electronic source]: https://ecosystem.siemens.com/about (access date: 24.10.2019).

20. SAP made the «ecosystem» open [Electronic source]: https://www.crn.ru/numbers/regnumbers/detail.php?ID=11310 (access date: 24.10.2019).

21. Partner ecosystem [Electronic Source]: https://www.bytemag.ru/articles/detail.php?ID=14219 (access date: 24.10.2019).

22. ANSYS Partner Ecosystem [Electronic source]: https://www.ansys.com/aboutansys/partner-ecosystem (access date: 24.10.2019).

23. Kidd, Paul T. Agile manufacturing: forging new frontiers. Addison-Wesley Longman Publishing Co. Inc. 1995.

24. Yusuf, Yahaya Y., Mansoor Sarhadi, Angappa Gunasekaran Agile manufacturing: The drivers, concepts and attributes // International Journal of production economics. № 62.12. 1999. P. 33-43.

25. Sherehiy B., Karwowski W., Layer J. K. A review of enterprise agility: Concepts, frameworks, and attributes // International Journal of industrial ergonomics. № 37.5. 2007. P. 445-460.

26. Sajad F., Zutshi A., O'Loughlin A. Understanding and development of supply chain agility and flexibility: a structured literature review // International Journal of Management Reviews. № 19.4. 2017. P. 379-407. 